\title{
Genetics in Medicine at Twenty
}

\author{
Robert D. Steiner, $\mathrm{MD}^{1,2,3}$
}

I am delighted to be appointed Editor-in-Chief (EIC) of Genetics in Medicine (GIM) as the journal completes its 20th year. This is a tremendous honor and I am humbled and thrilled that the search committee, editorial staff, and the American College of Genetics and Genomics (ACMG) leadership felt I was up to the task. GIM is, of course, the journal of the ACMG, the professional organization representing geneticists interested in medical genetics writ large. This appointment is especially rewarding considering my first manuscript submission to GIM was summarily rejected (note to early career authors-don't give up). This is a huge responsibility and one I don't take lightly. In my Deputy Editor role I've gotten a taste of the job since the retiring EIC, Jim Evans, was smart enough to leave GIM behind while on vacation, delegating operations to the deputy and editorial office staff. We hope GIM, in addition to being top of mind for ACMG members looking to publish their work, is also the go-to journal for nonmembers to submit their best work at the intersection of genetics and medicine (or better yet for such authors to become ACMG members, but now I'm advertising and I digress). The editorship is an awesome responsibility for several reasons including shepherding a journal that (1) serves as the primary instrument of publication for a major professional organization; (2) publishes Medical Genetics Practice Resources including technical standards for laboratories, clinical and laboratory practice resources and guidelines, and policy statements; and (3) selects the best of numerous outstanding manuscript submissions thereby helping define the field of genetics in medicine.

Why did I accept such an awesome responsibility and correspondingly large workload with nearly 850 annual submissions (many more than we can publish)? The journal is on very solid footing thanks to prior editors and staff. We owe a major debt of gratitude to Richard King, Founding Editor. It was his vision and that of ACMG leadership to begin this journey. GIM is a young journal that celebrated its 20th anniversary in grand style last year by publishing reviews from luminaries in the field. The second and retiring EIC, Jim Evans, took a nascent, albeit successful, journal to a very prominent position in medical/scientific publishing. $\mathrm{He}$ deserves much credit for developing GIM into one of the most prestigious journal titles in medical publishing. Jim is going to be a very hard act to follow. He is brilliant with an encyclopedic knowledge of human genetics. Jim is also a tireless editor, reading every article submitted, always remaining upbeat and encouraging to authors, and a fierce advocate for GIM. What I worry about, though, is that there may be an expectation to match Jim's wit; that's simply not possible, though I will try my best to carry on his tradition of good (occasionally sardonic) humor in the face of hard work along with occasional controversy and rare adversity. Jim would surely give much credit for the journal's success to his staff including Managing Editor Jan Higgins, along with Editorial Assistant Katie Murphy, ACMG's Communications Director Kathy Moran, News Editor Karyn Hede, and Cynthia Graber, our podcaster. He would also credit his section editors. Indeed, all deserve such credit, especially Jan Higgins. I know because I've had the pleasure to work with Jan, the staff, and section editors for the past dozen years.

I believe it's important for contributing authors, reviewers, and readers to know a bit about their EIC. Medical/scientific writing, manuscript reviewing, and journal editing have been integral to my career for more than 25 years. I've served on several journal editorial boards over the years and reviewed countless papers. I've had outstanding mentors in writing and editing over the years and with apologies to those excluded due to space limitations and memory lapses, I'd like to name a few. My first research mentor, Bill Busse, instilled in me early on a desire to express research results as clearly and concisely as possible. Bonnie Pagon helped me write my first medical genetics paper and I am forever grateful for her perfectionist tendencies. I think she used up more than one red pen editing my paper. Peter Byers taught me the art of simplifying difficult scientific concepts for a broad audience. John Opitz, a journal editor at the time, read every word of one of my first papers; I learned about the importance of style in writing and editing from him as he meticulously marked up the paper in red pencil. Finally, the initial manuscript I wrote with Bill Connor took its toll as I submitted over a dozen drafts before he was satisfied, but I do believe I learned the impact that a good editor can have on a manuscript.

In addition to writing and editing, I'm a practicing clinical geneticist and clinical biochemical geneticist. I see patients at

\footnotetext{
${ }^{1}$ University of Wisconsin School of Medicine and Public Health, Madison, Wisconsin 53706, USA; ${ }^{2}$ Marshfield Clinic Health System, Marshfield, Wisconsin 54449, USA; ${ }^{3}$ PreventionGenetics, Marshfield, Wisconsin 54449, USA. Correspondence: Robert D. Steiner (RDSteiner111@gmail.com)
} 
Marshfield Medical Center, where I'm also a consultant medical director for Marshfield Clinic Health System's insurance plan. I review genomic testing cases for PreventionGenetics. In addition, I continue to carry out research, teach, mentor, and see patients at the University of Wisconsin. I've been involved in basic science laboratory research but my research has mainly been clinical and translational. My experience along the way has included a traditional career path in academics at Oregon Health \& Science University, directing a research institute, and serving as chief medical officer for a start-up biotech company and as a medical director for a biochemical genetics laboratory.

The final reason why I accepted the offer to be EIC is that I believe this will be both fun and immensely rewarding. The opportunity to help shape our exciting field is one not to pass up. The best editors work hard and surround themselves with very smart people; I will be no exception. I've been asked about my vision for GIM. That vision isn't fully formed at this time as I believe it will mature and change with a few months under my belt in the job. However, I have certainly thought a lot about where I might like to see the journal go. These are exciting times in our field and in medical/scientific publishing, but also turbulent times. We must be nimble and able to adapt quickly to changing times. It's no secret that conflicts have arisen of late between countries and academic institutions and publishers over issues such as open access and the costs of contracts for access to large bundles of journals. These controversies are not going away anytime soon. What I can assure you is that we will stay abreast of these issues, work closely with our publisher Springer Nature to advocate for reasonable pricing and accessibility, and attempt to remain on the cutting edge of best practices in publishing. There are pressures for journals to stop printing hard copies. I still enjoy the feel of a print journal in hand and perusing print journals while traveling. Maybe I'm old school, but we will resist this pressure until it either becomes absolutely necessary to make the change, or a large majority of our readership tell us it's no longer necessary to print GIM.

So far, I've told you I want us to keep printing the journal, that I will advocate with the publisher for access to GIM at a fair cost, and that I will keep abreast of changes in medical/ scientific publishing. Although important, that doesn't represent a complete vision; a vision is based on goals. Our goal at GIM is simply to publish the best clinical and scientific manuscripts that tell the story of the critical place genetics holds in medicine and health care. This goal really drives everything. Sure, we would love to maintain or improve our excellent impact factor but that is not what drives us; rather, that's an outcome of publishing outstanding manuscripts. We want to continue to be the flagship publication for ACMG. GIM should remain on the cutting edge of advances in human and medical genetics. Our readership should look forward with great anticipation every month to receiving the online table of contents and/or print copy of GIM. We are a flagship journal of our publisher Springer Nature and recognition of this newly attained status is beginning to translate to tangibles such as promotion and marketing of the journal, significant resources for editors and staff, and prompt expert attention to issues that may arise in production to facilitate publication of error-free manuscripts in industry-leading turnaround times. Potential sponsors, advertisers, and donors should look to GIM with great interest as a top publication and potential recipient of their support, though we need to exercise great care in maintaining editorial autonomy and objectivity.

Do we have plans to make transformational changes at GIM? In a word, no. I think the old adage "don't fix something that ain't broke" applies. Nevertheless, to maintain our status as a top journal in a very competitive field, some changes are necessary. GIM will continue to utilize the services of an outstanding editorial board. Although there will be some natural attrition and replacements with new editors, massive changes in the constitution of our board are unwarranted as current members are doing a fantastic job. GIM will have a new emphasis on therapeutics; we are after all Genetics in Medicine. Recent and upcoming advances in therapeutics for genetic conditions are absolutely astounding. My hope is that investigators directing clinical trials in genetic conditions will look to GIM to publish their results. Likewise, researchers who develop novel therapeutic approaches will want to publish early phase trials in the journal. Although we are not a basic science journal, authors should be encouraged to submit groundbreaking basic science or animal model manuscripts with direct links to new therapeutic approaches. Even though there are journals devoted to gene therapy/gene editing, GIM encourages submissions of clinically relevant therapeutic reports utilizing those approaches for rare genetic conditions. Cancer genetics will also be emphasized as an area of interest going forward. GIM will continue to accept the following article types: innovative clinically relevant papers in contemporary genetic medicine, including such areas as clinical and laboratory genetics practice; gene discovery and genomics; chromosome abnormalities and copy-number variation; biochemical genetics/metabolic diseases; singlegene disorders; genetics of common diseases; health services/implementation research as it relates to genetics; pharmacogenomics; public health genetics, including screening and economics; applications of technology to medical genetics; bio- and clinical informatics and biobanking; important genetic counseling issues; ethical, legal, and social implications of genetics; and human medical genetics history and education. We will also encourage submissions describing the natural history of rare diseases because this is critical to therapeutics. Reports of clinical utility of genetic testing are welcomed because this is the current standard for genetic testing reimbursement. These are just some of the ideas we have for shaping GIM in the coming years. Plans are developing to roll out additional new initiatives over the coming months and years. After all, although we've given you a good sense of where we think we're going, we don't want to take all the suspense away. I also can't presume to know exactly where the field is going and we'd like the freedom to alter the vision as currently presented. The most important 
point I can make is that the editorial board, ACMG, and the journal staff want to encourage all of you readers and authors to persevere in your important clinical and research efforts and think of GIM as the place to submit your work.

Innovation is an important theme for journals to embrace. We will continue to take creative approaches to publishing. We at GIM will develop a comprehensive communications strategy working hand in hand with Kathy Moran and her staff to further expand our social media/electronic publishing presence (Facebook, Twitter, podcasts, etc.) and use of technology to integrate electronic publishing and social media, among other strategies. We accept manuscripts whose data was previously included on preprint servers. GIM will use the latest technologies available in publishing to improve turnaround times, along with working to develop a new rapid publication option for your results that deserve and require the fastest turnaround. We will pursue an option for direct streamlined submission from preprint servers. One of the more radical approaches to be embraced is collaboration with other journals. Editors of other genetics journals are our friends and colleagues. Discussions with these editors, including but not limited to Bruce Korf (American Journal of Human Genetics), Max Muenke (American Journal of Medical Genetics), and Eva Morava (Journal of Inherited Metabolic Disease), have begun. Similarly, we will leverage our publisher's ownership of other high impact journals to explore best practices, partnerships, and collaborative projects with Nature, Nature Genetics, Nature Medicine, Nature Reviews Genetics, and Scientific American, to name a few. I envision development of editorial internships, rotating clerkships, and training at GIM for those interested in careers in publishing or wanting to gain editorial and publishing experience. Interest from readers in such training will help inform and guide development of these opportunities so we welcome queries and suggestions. Finally, we are considering adding a distinguished advisory board to assist GIM in further refinement of the journal's mission, vision, and strategic plans, and in editorial and ethical decisions when needed.

In conclusion, I am delighted to have the opportunity to serve you - the readers, reviewers, authors, and supporters of GIM; ACMG; and the staff and editors-in leading this great journal. I look forward to hearing your ideas for where you think the journal should go, and for reading your submissions to the journal. My friend Jim Evans has been a wonderful mentor and role model. Furthermore, Jim leaves the editorship of GIM at the top of his game with the journal stronger than ever. I hope that I will have the insight, ability, and wisdom to follow suit.

\section{DISCLOSURE}

R.D.S. has equity interest in and has received consulting fees from Acer Therapeutics and Censa Pharmaceuticals; has served as a consultant with compensation for Retrophin; and is principal investigator of an investigator-initiated observational research study funded by Alexion via a contract with Marshfield Clinic Health System. In the past five years he has received travel support from Pfizer and consulting fees from Raptor, Biomarin, Health Advances, Precision for Value, and Best Doctors. He is an employee of PreventionGenetics, and has served as an expert reviewer for legal cases related to malpractice claims. He has one patent awarded but not licensed (no revenue) and a second patent pending, both in the area of newborn screening for sterol and bile acid disorders. 